Research Article

\title{
Epidemiology of pelvic fracture in the emergency room at Dr. Soetomo General Hospital between 2016-2018
}

Yuga Rahmadana ${ }^{*}$, M. Zaim Chilmi ${ }^{1}$

1) Department of Orthopaedic and Traumatology, Faculty of Medicine Universitas Airlangga- Dr.Soetomo General Hospital, Surabaya

\section{A R T I C L E I N F O \\ Submitted : $24^{\text {th }}$ February 2021 \\ Accepted : $2^{\text {nd }}$ August 2021 \\ Published : 25 $5^{\text {th }}$ January 2022}

\section{Keywords:}

Epidemiology Pelvic Trauma, Prevention Pelvic Trauma, Management Pelvic Trauma

*Correspondence:

yugarahmadana@gmail.com

This is an Open acces article under the CC-BY license

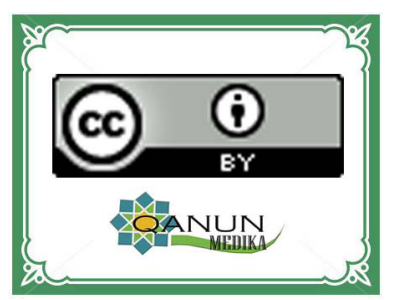

\begin{abstract}
Pelvic fracture is a rare case. The incidence is about $3 \%$ to $8 \%$ of the whole kind of fractures. The most common cause is high energy trauma and is associated with multi-trauma. The amount of pelvic trauma patients is 63,000 and is associated with increased mortality rates. The scientific data is needed because it is helpful for trauma prevention and management. This research is a descriptive observational study that examines the epidemiology of pelvic trauma. The population was patients with pelvic trauma who came to the ER RSUD Dr. Soetomo in 2016-2018. The total sample was 229 patients. A total of 149 patients $(65.1 \%)$ were male, and 80 patients $(34.9 \%)$ were female. Traffic accidents caused 173 patients $(76 \%)$ cases. Tile A classification was most frequent in 117 patients $(51.1 \%)$. There were 178 patients $(77.7 \%)$ who were multi-trauma patients. The most common treatment was pelvic bandage with 95 patients (41.5\%). There were 178 multitrauma patients, 109 patients $(61.2 \%)$ who underwent emergency surgery for trauma, and 69 patients (38.8\%) who did not. The most common cause of pelvic fracture in Dr. Soetomo general hospital during 2016-2018 was trauma with high energy due to traffic accidents. The most common type of pelvic fracture was Tile A. The more severe the pelvic trauma, the treatment should be more aggressive.
\end{abstract}




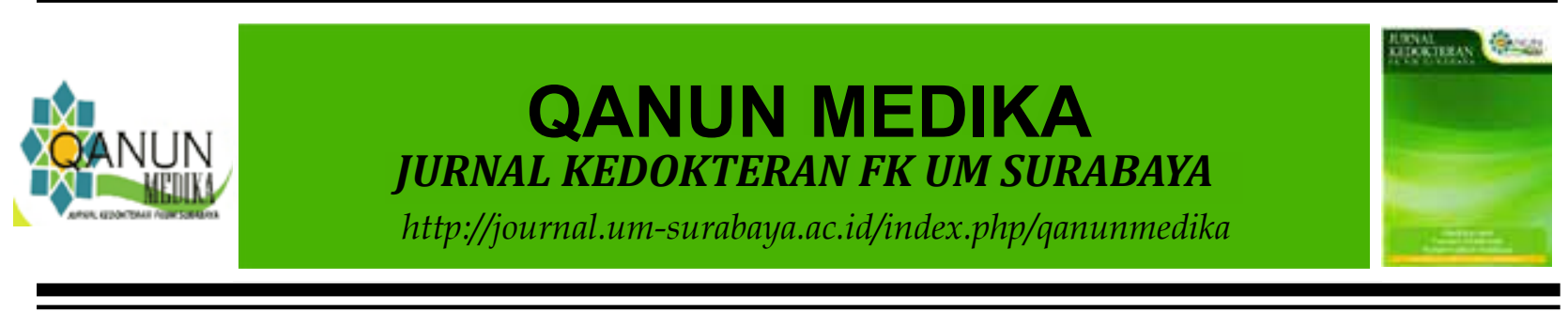

\section{INTRODUCTION}

Fracture pelvic is one of the main results of low energy trauma, such as falls, especially in older people. Fracture pelvic is closely associated with morbidity and mortality, with an $8-27 \%$ mortality rate of all cases (Andrich et al., 2015). Fracture pelvic has been reported to occur in $3 \%$ to $8 \%$ of all bone injuries and is often associated with high-energy trauma such as high-speed motor vehicle accidents or falls from heights in younger people. From Epidemiological studies of fracture pelvic, all incidence is $28-37$ per 100,000 people for a year (Verbeek et al., 2018).

The main goal of managing fracture pelvic is to reduce the risk of mortality. Severe pelvic trauma can cause significant complications. A recent analysis of more than 63,000 trauma patients showed that fracture pelvic is associated with a high mortality rate (Sathy et al., 2009). There is a significant variability related to risk factors that increase mortality in pelvic trauma. In $15-30 \%$, patients with a high-energy pelvic fracture are commonly unstable hemodynamics. It is directly associated with blood loss due to pelvic trauma. Extensive bleeding is a major cause of death in fracture pelvic (Schulman et al., 2010). The high-power mode of injury is closely related to the mortality rate in fracture pelvic. Several factors influence the prognosis, such as characteristics, diagnosis, and management of fracture pelvic. Therefore, it should be determined immediately to decrease the mortality of these patients. (Breuil, Roux and Carle, 2016). However, there is no data on the incidence rate and characteristics of Dr. Soetomo Hospital and how to handle it in emergency cases.

Therefore, it is important to carry out epidemiological research in orthopedic trauma because epidemiological data can accelerate diagnosis and management that improve the prognosis. This research aimed to describe the distribution of gender, age, the motion of injury (MOI), hemodynamic condition, classification of fracture pelvic, type of injury, and treatment of pelvic trauma patients in Dr.Soetomo general hospital during 2016-2018. In addition, this study aimed to produce scientific data that can be useful for preventing and managing trauma in the population.

\section{METHODS}

This research was a descriptive observational study that examines the epidemiology of pelvic trauma. This study population was patients with pelvic trauma who came to the ER RSUD Dr. Soetomo in 2016-2018. This study's sample was a total sampling, all patients with pelvic trauma who went to the emergency room Dr. Soetomo in 2016-2018. The patient characteristics such as gender, age, MOI, hemodynamic condition, classification of fracture pelvic, type of injury and treatment were included in this study. Data of this study was taken from the recapitulation of the patient's medical records. Data was manually collected, and the data were analyzed descriptively; it was first selected, edited, coded, and tabulated. Descriptive data were displayed in tables and graphs and analyzed variables (gender, age, MOI, hemodynamic condition, classification of fracture pelvic, type of injury, and treatment). This study had received Ethical Clearance Information No. $0175 / \mathrm{LOE} / 301.4 .2 / \mathrm{X} / 2020$ issued by the Research Commission of the Dr. Soetomo Hospital Surabaya.

\section{RESULTS}

This retrospective study was conducted with a descriptive design of pelvic trauma profiles in the Emergency Room of Dr. Soetomo Hospital Surabaya in 2016-2018 with a total sample of 229 patients. 
Table 1. Distribution of sample frequencies by gender and age

\begin{tabular}{|c|c|c|}
\hline No. & Characteris tic & Amount (\%) \\
\hline \multirow{4}{*}{1.} & Gender & \\
\hline & Male & $149(65.1 \%)$ \\
\hline & Women & $80(34.9 \%)$ \\
\hline & Total & $229(100 \%)$ \\
\hline \multirow[t]{10}{*}{2.} & Age & \\
\hline & $0-10$ & $5(2 \%)$ \\
\hline & $11-20$ & $55(24 \%)$ \\
\hline & $21-30$ & $45(20 \%)$ \\
\hline & $31-40$ & $44(19 \%)$ \\
\hline & $41-50$ & $45(20 \%)$ \\
\hline & $51-60$ & $23(10 \%)$ \\
\hline & $61-70$ & $9(4 \%)$ \\
\hline & $>70$ & $3(1 \%)$ \\
\hline & Total & $229(100 \%)$ \\
\hline \multirow[t]{5}{*}{3.} & MOI & \\
\hline & Traffic Accident & $173(76 \%)$ \\
\hline & Fallen & $51(22 \%)$ \\
\hline & Work accident & $5(2 \%)$ \\
\hline & Total & $229(100 \%)$ \\
\hline
\end{tabular}

According to table 1, out of 229 patients in this study, 149 patients $(65.1 \%)$ were male, while the remaining 80 patients $(34.9 \%)$ were female with a ratio of 1.8: 1 . The mean patient age was 33.5 years, with the youngest patient was eight years, and the oldest age was 74 years. Traffic accidents are the leading cause of pelvic fractures $(76 \%)$.

As shown in Table 2, based on pelvic trauma diagnosis classification, most pelvic trauma cases were patients with the Tile Aclassification, namely 117 patients $(51.1 \%)$, followed by the APC 2 classification of 26 patients $(11.4 \%)$. The third most classification of pelvic trauma is the APC 1 classification of 23 patients $(10 \%)$ and followed by LC 2 classification of 19 patients $(8.3 \%)$, LC 1 as many as 15 patients $(6.6 \%)$, Vertical Shear as many as 14 patients $(6.1 \%)$, APC 3 was ten patients (4.4\%) and LC 3 was five patients $(2.2 \%)$.

Table 3 shows the distribution of the type of therapy based on hemodynamic conditions. Mostly, the patients were 182 patients with stable hemodynamic conditions, 85 patients were subjected to conservative therapy, 83 


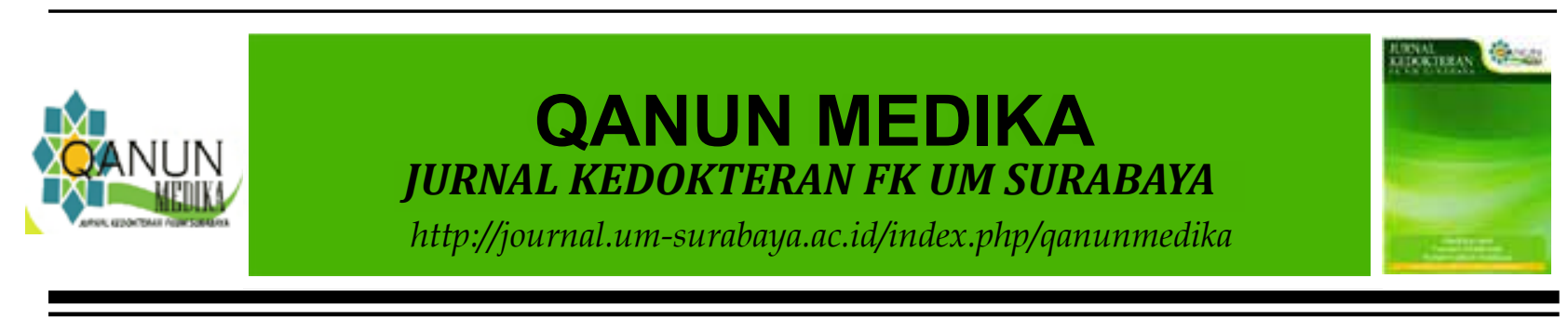

patients had a pelvic bandage, 4 patients had C-Clamp insertion, 10 patients had external fixation. 47 patients with unstable hemodynamic conditions, 8 patients received conservative therapy, 12 received pelvic bandage therapy, 17 received C-Clamp insertion, and 10 received external fixation

Based on the type of trauma, from 229 patients, 178 patients, or $77.7 \%$ were multi-trauma patients. In contrast, the remaining $22.3 \%$ or 51 patients were single-trauma patients. The most common type of comorbid trauma to pelvic trauma was another extremity trauma with 68 cases $(38.2 \%)$. This study found that the highest number of other trauma surgeries performed by C-clamp installation was in other orthopedic trauma cases, as many as 5 patients out of a total of 14 patients. Meanwhile, the most other trauma surgery that performed external fixation on the pelvis was urogenital trauma surgery with abdominal trauma surgery as many as 4 out of 17 patients. The pelvic bandage was mainly placed on the patient's pelvis, who underwent surgery on other extremities in 19 out of 35 patients. Conservative therapy was mostly performed on patients who underwent surgery in other orthopedic fields, in 16 patients from 35 .

Table 2 Distribution of sample frequencies based on the classification of pelvic trauma diagnoses

\begin{tabular}{llcc}
\hline No & Pelvic Trauma Classification & Amount (n) & $(\%)$ \\
\hline 1 & Tile A & 117 & $51,1 \%$ \\
2 & APC 1 & 23 & $10,0 \%$ \\
3 & APC 2 & 26 & $11,4 \%$ \\
4 & APC 3 & 10 & $4,4 \%$ \\
5 & LC 1 & 15 & $6,6 \%$ \\
6 & LC 2 & 19 & $8,3 \%$ \\
7 & LC 3 & 5 & $2,2 \%$ \\
8 & Vertical Shear & 14 & $6,1 \%$ \\
& Total & 229 & $100 \%$ \\
\hline
\end{tabular}

Table 3. Distribution of sample frequencies based on the classification of pelvic trauma diagnoses

\begin{tabular}{ccccccc}
\hline & \multicolumn{5}{c}{ The rapy } \\
\cline { 3 - 7 } & & Cons ervative & $\begin{array}{c}\text { Pelvic } \\
\text { Bandage }\end{array}$ & $\begin{array}{c}\text { C- } \\
\text { Clamp }\end{array}$ & $\begin{array}{c}\text { External } \\
\text { Fixation }\end{array}$ & Total \\
\hline Hemodynamic & Stable & 85 & 83 & 4 & 10 & 182 \\
Condition & Unstable & 8 & 12 & 17 & 10 & 47 \\
& Total & 93 & 95 & 21 & 20 & 229 \\
\hline
\end{tabular}




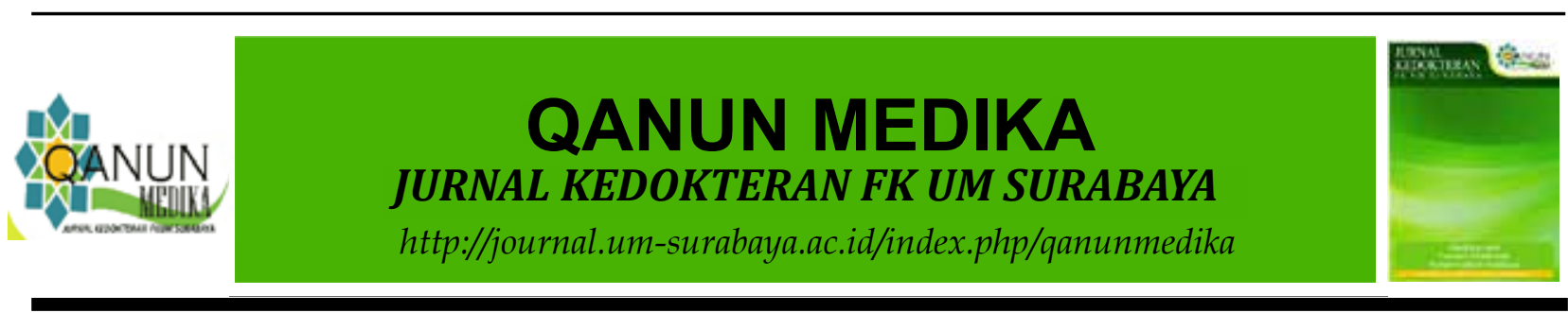

\begin{tabular}{llccccc}
\hline & & \multicolumn{5}{c}{ Treatment } \\
\cline { 3 - 7 } & & $\begin{array}{c}\text { C- } \\
\text { Clamp }\end{array}$ & $\begin{array}{c}\text { External } \\
\text { Fixation }\end{array}$ & $\begin{array}{c}\text { Pelvic } \\
\text { Bandage }\end{array}$ & $\begin{array}{c}\text { Conservative } \\
\text { Total }\end{array}$ \\
\hline Ope rations & $\mathbf{A}$ & 5 & 2 & 19 & 16 & 42 \\
with other & $\mathbf{B}$ & 0 & 0 & 3 & 3 & 6 \\
trauma & $\mathbf{C}$ & 2 & 1 & 7 & 2 & 12 \\
& $\mathbf{D}$ & 0 & 0 & 2 & 1 & 3 \\
& $\mathbf{E}$ & 1 & 1 & 6 & 2 & 10 \\
& $\mathbf{A}+\mathbf{B}$ & 0 & 0 & 1 & 3 & 4 \\
$\mathbf{A}+\mathbf{C}$ & 1 & 0 & 0 & 0 & 1 \\
& $\mathbf{A}+\mathbf{E}$ & 3 & 3 & 1 & 4 & 10 \\
& $\mathbf{B}+\mathbf{C}$ & 0 & 0 & 0 & 1 & 1 \\
& $\mathbf{B}+\mathbf{E}$ & 0 & 0 & 1 & 0 & 1 \\
& $\mathbf{C}+\mathbf{E}$ & 1 & 4 & 2 & 3 & 10 \\
& $\mathbf{A}+\mathbf{B}+\mathbf{E}$ & 0 & 1 & 0 & 0 & 1 \\
& $\mathbf{A}+\mathbf{C}+\mathbf{E}$ & 1 & 2 & 0 & 0 & 3 \\
& $\mathbf{A}+\mathbf{D}+\mathbf{E}$ & 0 & 1 & 0 & 0 & 1 \\
& $\mathbf{B}+\mathbf{C}+\mathbf{E}$ & 0 & 0 & 1 & 0 & 1 \\
& $\mathbf{A}+\mathbf{B}+\mathbf{C}+\mathbf{E}$ & 0 & 2 & 0 & 0 & 2 \\
& Total & 14 & 17 & 43 & 35 & 109 \\
\hline
\end{tabular}
*Note
A: Other extremity operation
B: Thorax operation
C: Urogenital operation
D: Head and neck operation
E: Abdomen operation

\section{DISCUSSION}

The result of this study is consistent with fracture pelvic epidemiology data in other countries, where most patients are male, and the most common age range is $15-25$ years. (Wedel and Galloway, 2013). Another study also obtained similar results where pelvic trauma in men was three times more than in women. This is due to their high participation in physical activities such as construction work, motorbike driving, and other activities. In another study by Eluwa et al., it was also shown that the number of men who experienced traumatic events was greater than that of women. When driving, this might be due to men being often impatient, aggressive, and losing concentration (Eluwa et al., 2010). Also, men have a higher risk of traffic accidents (Young, Birrell, and Stanton, 2011).
Traffic accidents are the most common mode of injury of pelvic trauma in this study. This is also consistent with other studies, which further confirm that pelvic trauma is closely related to high energy trauma (Breuil, Roux and Carle, 2016). This study's results are also in line with research conducted by Ghosh et al., which showed that traffic accidents cause as many as $77 \%$ of pelvic trauma. Research conducted by Yang et al. 2014 in Taiwan from 2000 - 2011 also showed that $62 \%$ of pelvic trauma causes were traffic accidents. (Yang et al., 2014; Ghosh et al., 2019). Data from the World Report on Traffic Injury Prevention, the death rate due to traffic accidents reaches 1.2 million people each year. The causes of the high number of traffic accidents in developing countries are the steady increase of motorized vehicles, poor enforcement of traffic safety regulations, and 


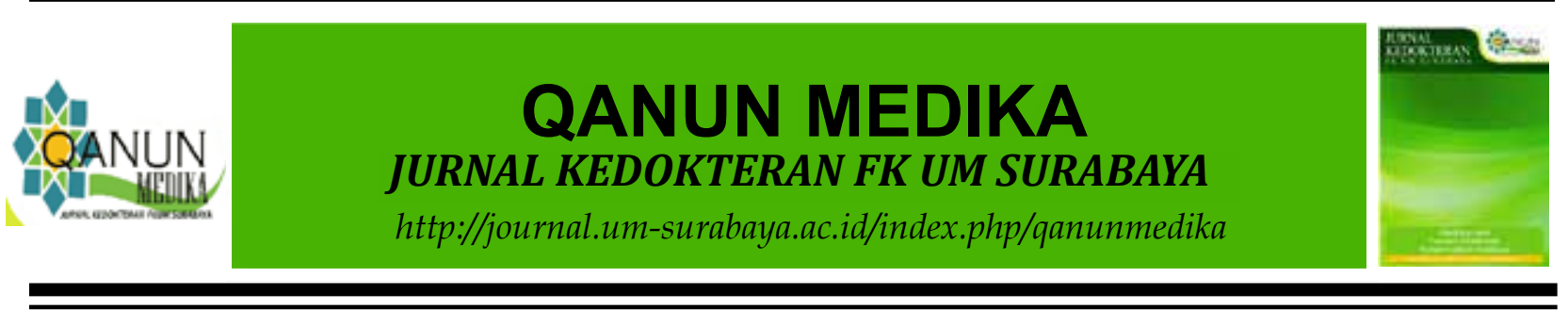

poor road infrastructure. (Young, Birrell and Stanton, 2011; Organization, 2015)

From the data obtained, $82,1 \%$ of patients came with multi-trauma, with about $79,5 \%$ stable hemodynamic conditions. The most complicated cases of pelvic trauma in this study were other limb trauma (multiple trauma), in about $38.2 \%$, followed by trauma to other organ systems, which could include trauma to the head and neck, trauma to the thorax, trauma to the urogenital area, trauma to the gastrointestinal area. This result is in line with a study conducted by Yang et al. with 36,594 patients, 23,888 patients experienced multi-trauma, where the most common accompanying trauma was trauma to other extremities in about $60.6 \%$, followed by head injury for $17.6 \%$, and the rest was trauma to thoracic, abdominal and urogenital. Another study in India also obtained similar results where trauma to the other extremities is the most common comorbid trauma to pelvic trauma (Yang et al., 2014; Vidyarthi and Nayak, 2018). An isolated trauma to the pelvis is extremely rare because of pelvic trauma caused by a high-energy injury. High energy trauma transmits the force to the bones and other organs, so pelvic trauma is often accompanied by other accompanying trauma. (Ghosh et al., 2019).

The Tile and Young and Burgess classifications were used to classify each of the pelvic injuries in this study, where these two classifications can be related. Tile A is a stable pelvic trauma condition. Tile B is a partially unstable pelvic trauma condition, where Tile $\mathrm{B} 1$ is the same as Young and Burgess APC I and APC II, Tile B2 is the same as Young and Burgess LC I and LC II, Tile B3 is the same as Young and Burgess LC III. Furthermore, Tile $\mathrm{C}$ is the same unstable pelvic trauma condition as the Young and Burgess Vertical Shear (VS) and APC III. (Tosounidis et al., 2015). Based on the type of trauma, Tile A (Stable) trauma was the most common type, accounting for $51.1 \%$ of the total patients. Whereas for type B Tile, a total of $40.7 \%$ of the total patients were obtained, with the distribution for Tile-type B1 as much as $21.4 \%$ (APC $110 \%$ and APC $211.4 \%$ ), Tile-type B2 as much as $14.9 \%$ (LC I was $6.6 \%$ and LC II was $8.3 \%$ ), Tile-type B3 was $2.2 \%$ (LC III was $2.2 \%$ ).

Moreover, for Tile Type C, $10.5 \%$ of the total patients were obtained (APC III 4.4\% and VS $6.1 \%$ ). This result is in line with a study conducted by Pereira et al. in Brazil where Tile A pelvic trauma was the largest classification of pelvic trauma at $54.5 \%$, followed by Tile B and Tile C pelvic trauma. (Pereira et al., 2017).

In this study, 20 patients $(8.7 \%)$ had pelvic trauma who underwent external fixation and 21 patients $(9.2 \%)$ with C-clamp. These results are similar to that of a study conducted by Pereira et al., wherein $9.1 \%$ of patients had external fixation, and $7.6 \%$ of patients had C-clamp insertion. External fixation provides temporary pelvic ring stability that is rigid and serves as an adjunct to control early bleeding in hemodynamically unstable pelvic ring disorders. External fixation of the anterior via the iliac crest or the supra-acetabular route provides adequate transient pelvic stability in the APC-II / -III and LC-II / -III injury patterns. A posterior pelvic C-clamp may be indicated to control bleeding in vertical shear injuries with sacroiliac joint disorders. Pelvic C-clamp application is contraindicated in communitive and transformational sacral trauma, iliac wing trauma, and type LC pelvic trauma. (Magnone et al., 2014; Weaver and Heng, 2015).

There were some limitations to this study. Firstly, the number of samples was relatively small. Future studies should involve a larger sample size. Secondly, the year span of operation was too short. The length of data is more representative of the real data about the case. Thirdly, this research is a descriptive study 
that is needed to comparison study to improve the study.

\section{CONCLUSION}

The most common cause of trauma to the pelvis is trauma with high energy due to traffic accidents. Men had 1.8 times more pelvic trauma than women. Most pelvic trauma types are Tile A. Pelvic trauma patients who experience trauma elsewhere (multi-trauma) are more likely to experience more than just pelvic trauma (single trauma). The more severe the pelvic trauma suffered (see classification), the more aggressive the therapy was. The more hemodynamically unstable the patient, the more aggressive the pelvic trauma therapy was. If an invasive treatment is performed on accompanying trauma in the abdominal and urogenital area, then therapy for pelvic trauma will be more aggressive.

\section{REFERENCES}

Andrich, S. et al. (2015). Epidemiology of pelvic fractures in Germany: considerably high incidence rates among older people, PLoS One, 10(9), p. e0139078.

Breuil, V., Roux, C. H. and Carle, G. F. (2016). Pelvic fractures: epidemiology, consequences, and medical management, Current opinion in rheumatology, 28(4), pp. 442-447.

Eluwa, M. A. et al. (2010). Disposition of fractures and dislocations among road accident victims in rivers and bayelsa states of Nigeria from 1992-2005, IJE, $8(1)$.

Ghosh, S. et al. (2019). Epidemiology of pelvic fractures in adults: Our experience at a tertiary hospital, Chinese journal of traumatology, 22(3), pp. 138-141.

Magnone, S. et al. (2014). Management of hemodynamically unstable pelvic trauma : results of the first Italian consensus conference ( cooperative guidelines of the Italian Society of Surgery, the Italian Association of Hospital Surgeons , the Multi-specialist Italian Society of Young Surgeons, the Italian Society of Emergency Surgery and Trauma, the Italian Society of Anesthesia, Analgesia , Resuscitation and Intensive Care , the Italian Society of Orthopaedics and Traumatology, the Italian Society of Emergency Medicine, the Italian Society of Medical Radiology -Section of Vascular and Interventional Radiologyand the World Society of Emergency Surgery ), pp. 1-8.

Organization, W. H. (2015). Global status report on road safety 2015. World Health Organization.

Pereira, G. J. C. et al. (2017). Epidemiology of pelvic ring fractures and injuries, Revista Brasileira de Ortopedia, 52(3), pp. 260269.

Sathy, A. K. et al. (2009). The effect of pelvic fracture on mortality after trauma: an analysis of 63,000 trauma patients, JBJS, 91(12), pp. 2803-2810.

Schulman, J. E. et al. (2010). Pelvic ring fractures are an independent risk factor for death after blunt trauma, Journal of Trauma and Acute Care Surgery, 68(4), pp. 930-934.

Tosounidis, T. H. et al. (2015). The use of buttress plates in the management of acetabular fractures with quadrilateral plate involvement: is it still a valid option?, International orthopaedics, 39(11), pp. 2219-2226.

Verbeek, D. O. et al. (2018). Pelvic fractures in the Netherlands: epidemiology, characteristics and risk factors for inhospital mortality in the older and 


\section{QANUN MEDIKA \\ JURNAL KEDOKTERAN FK UM SURABAYA \\ http://journal.um-surabaya.ac.id/index.php/qanunmedika}

younger population, European Journal of Orthopaedic Surgery \& Traumatology, 28(2), pp. 197-205.

Vidyarthi, D. A. and Nayak, D. (2018). Study of incidence and prevalence of pelvic fractures in Central India, $J$ Med Sci Clin Res.

Weaver, M. J. and Heng, M. (2015). Orthopedic Approach to the Early Management of Pelvic Injuries Orthopedic Approach to the Early Management of Pelvic Injuries, (March). doi: 10.1007/s40719014-0005-4.

Wedel, V. L. and Galloway, A. (2013). Broken bones: anthropological analysis of blunt force trauma. Charles $\mathrm{C}$ Thomas Publisher.
Yang, N.-P. et al. (2014). Epidemiology of hospitalized traumatic pelvic fractures and their combined injuries in Taiwan: 2000-2011 National Health Insurance data surveillance, BioMed research international, 2014.

Young, M. S., Birrell, S. A. and Stanton, N. A. (2011). Safe driving in a green world: A review of driver performance benchmarks and technologies to support 'smart' driving, Applied ergonomics, 42(4), pp. 533-539. 